\title{
Delayed reinforcement and pigeons' performance on a one-key matching-to-sample task
}

\author{
RALPH W. RICHARDS \\ Colorado State University, Fort Collins, Colorado
}

\begin{abstract}
Pigeons were trained on a one-key matching-to-sample task with vertical and horizontal lines as the sample and comparison stimuli. Matching accuracy decreased with increases in the duration of the delay interval between offset of the comparison and delivery of the trial outcome. In general, this reduction in matching was produced by an increase in response rates to nonmatching comparisons as well as by a decrease in response rates to matching comparisons.
\end{abstract}

Numerous studies (see reviews by Carter \& Werner, 1978; Grant, 1981a; Riley, 1984; Roberts \& Grant, 1976) have examined pigeons' learning of and performance on the conditional discrimination known as the delayed matching-to-sample task. Sessions are usually conducted in a Skinner box and contain a series of trials that are presented in mixed order and separated by an intertrial interval. In the widely studied three-key matching task, the sample stimulus is first briefly presented on the center key; then two comparison stimuli, one being identical to the sample, are projected onto the side keys. If the pigeon pecks the comparison that is identical to or matches the previous sample, a reinforcer is delivered. Choice of the nonmatching comparison is not reinforced and often produces a timeout. In the past few years, researchers have shown an increasing interest in the one-key version of matching (e.g., Grant, 1981b; Kendrick, Rilling, \& Stonebraker, 1981; Nelson \& Wasserman, 1978; Richards \& Bowers, 1985; Stonebraker \& Rilling, 1982; Wasserman, 1976). In this version, each trial contains a single comparison stimulus that is presented for several seconds. If the comparison matches the previous sample, responding during the comparison is reinforced according to some intermittent schedule. If the comparison does not match the sample, responding to the comparison is not reinforced. Thus, the three-key and one-key variants of matching are like standard simultaneous and successive discriminations, respectively, except that reinforcement for responding to a stimulus (the comparison) depends on the nature of the previous stimulus (the sample). In the threekey task, matching accuracy is measured by the percent of choices that are made to the correct comparison. However, a discrimination ratio, based on relative response rates to matching and nonmatching comparisons, is usually computed in the one-key version.

A variety of factors affect the accuracy of pigeons' performance on these matching tasks. For example, short sample durations (Grant, 1976; Maki \& Leith, 1973; Nel-

Reprints may be obtained from Bill Richards, Department of Psychology, Colorado State University, Fort Collins, CO 80523. son \& Wasserman, 1978), short intertrial intervals (Nelson \& Wasserman, 1978; Roberts \& Kraemer, 1982), long delays between sample offset and comparison onset (Berryman, Cumming, \& Nevin, 1963; Farthing, Wagner, Gilmour, \& Waxman, 1977; Nelson \& Wasserman, 1978; Roberts \& Kraemer, 1982), and compound samples (Maki \& Leith, 1973; Richards \& Bowers, 1985) hinder matching on both one-key and three-key tasks. Interestingly, poor performance on the one-key version is more often produced by an increase in response rates to nonmatching comparisons than by a decrease in response rates to matching comparisons.

Wilkie and Spetch (1978) employed the three-key task and obtained poorer matching under conditions of delayed reinforcement. The present study was concerned with whether delayed consequences would also hinder matching on the one-key task and, if so, whether this would occur because of increased response rates to nonmatching comparisons (see above) and/or decreased response rates to matching comparisons. In regard to the latter possibility, numerous studies (e.g., Ferster \& Hammer, 1965; Morgan, 1972; Pierce, Hanford, \& Zimmerman, 1972) have found that delaying reinforcement decreases the response rates maintained by various schedules of intermittent reinforcement.

\section{METHOD}

\section{Subjects}

Four mature female White Carneaux pigeons were maintained at $80 \%$ of their free-feeding weights. Each pigeon had extensive training on several versions of the one-key matching task with color and line stimuli, but none had received any trial-outcome delays. A fifth pigeon was discarded very early in the project because of difficulties in maintaining its weight near $80 \%$ level.

\footnotetext{
Apparatus

Each of the four similar Skinner boxes (approximately $14 \times 14 \times 14$ in.) was housed in a separate sound- and light-attenuating chamber. The Skinner boxes were constructed mainly of plywood; however, the door was Plexiglas, and the intelligence panel, containing three LVE keys and a food hopper, was metal. An in-line display cell, equipped with 1820 bulbs, permitted projections of a homogeneous white light, three vertical white lines $(\mathrm{V})$, and three horizontal white lines $(\mathrm{H})$ onto the center key. The side keys were not used. A houselight (1820), mounted above
} 
the center key, provided general illumination, and a red pilot light (1820), mounted on the back wall, was illuminated during the outcome-delay intervals. Each Skinner box was interfaced to an Apple computer, and all equipment was located in one room.

\section{Procedure}

A trial began when the center key was illuminated by the presample stimulus (the homogeneous white light). After five responses, one of two sample stimuli $(\mathrm{V}$ or $\mathrm{H})$ was presented. The first response after $5 \mathrm{sec}$ darkened the key for $.5 \mathrm{sec}$, after which one of two comparison stimuli ( $\mathrm{V}$ or $\mathrm{H})$ appeared. If the comparison stimulus matched the justremoved sample, the first response after $5 \mathrm{sec}$ produced 3 -sec access to mixed grain. If the sample and comparison did not match, the comparison was removed automatically after $5 \mathrm{sec}$ and a 3-sec timeout occurred. The chamber was dark during the timeout.

In each session, each of the four trial types ( $\mathrm{V}$ or $\mathrm{H}$ sample followed by a $\mathrm{V}$ or $\mathrm{H}$ comparison) was presented 20 times; the order of presentation was mixed. An intertrial interval, in which only the houselight was illuminated, separated the trials. The duration of the intertrial interval was $25 \mathrm{sec}$, except that it could not terminate within $5 \mathrm{sec}$ of a keypeck.

For the first 65 sessions, the outcomes were not delayed, and the reinforcer or timeout occurred as the comparison was removed. Next, all subjects were trained with delay durations of $1,2.5,5$, and $10 \mathrm{sec}$. All subjects except S-3398 then received 15 - and 20-sec delays. Finally,
S-1918 and S-3378 were trained with a 25 -sec delay. Delay durations were presented in an ascending sequence, and each duration was in effect for $\mathbf{2 5}$ sessions. During the delay before reinforcement and timeout, only the red pilot light was illuminated and responding was nonfunctional. The houselight remained lit throughout the session, except for delay and timeout periods.

\section{RESULTS}

Figure 1 shows each bird's mean performance during the last five sessions under the various durations of trialoutcome delay. The dependent variable in the left panels is a discrimination ratio based on the formula $\mathrm{m} /(\mathrm{m}+\mathrm{n})$, where $m$ and $n$ represent response rates during the first $5 \mathrm{sec}$ of the comparisons that matched and did not match the previous sample, respectively. A discrimination ratio of 1.00 indicates perfect discrimination performance, and a ratio of .50 indicates chance performance (i.e., equal response rates during matching and nonmatching comparisons). The left panel shows that the accuracy of all subjects decreased as the delay duration increased. For S-3419 and S-1918, accuracy changed only slightly as de-

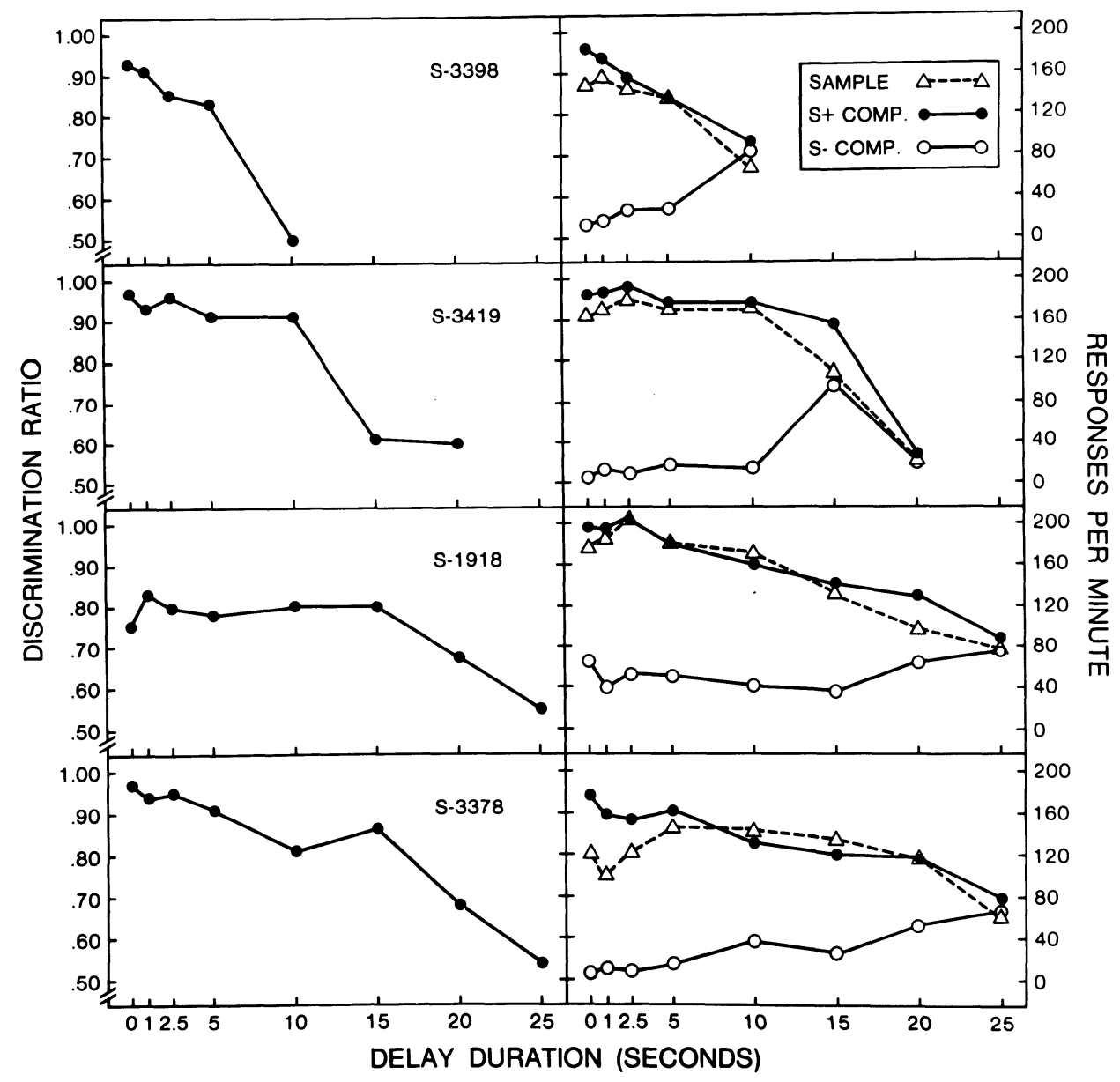

Figure 1. Performance on the matching task as a function of the duration of reinforcement and timeout delay. The triangles represent response rates to the sample. The closed circles indicate response rates to comparisons that matched the previous sample (S+Comp), and the open circles indicate response rates to comparisons that did not match the previous sample (S-Comp). 
lay durations were increased up to 10 and $15 \mathrm{sec}$, respectively, but substantial deterioration in performance occurred at the longer delay durations.

The right panel shows response rates during the first $5 \mathrm{sec}$ of the samples (open triangles), matching comparisons (closed circles), and nonmatching comparisons (open circles). Changes in response rates during the sample and matching comparison showed a similar pattern: as delay duration increased, responding slowed down. In contrast, response rates to nonmatching comparisons increased as the duration of the delay increased; however, S-3419's response rates to the nonmatching comparison decreased at the longest delay duration.

Although time to complete the required five responses to the presample stimulus was not recorded, casual observations indicated that clear changes occurred. With immediate reinforcement and short delay durations, the response requirement was quickly completed, usually in $1 \mathrm{sec}$ or less. Under the longer delay durations, latencies were frequently many minutes, and birds often required several hours to complete their sessions.

\section{DISCUSSION}

Accuracy of performance on the one-key matching-to-sample task was decreased by delaying the delivery of food and timeout. Although short delays produced little or no decrement, long delays reduced performance to near chance. It should be noted that birds in the present study had extensive training with immediate reinforcement prior to the introduction of the delay conditions and that durations were presented in an ascending sequence. Perhaps a steeper delay function would have been obtained if the birds were less experienced or if the durations had been presented in a different sequence. On the other hand, a flatter function might have been obtained if different delay stimuli had occurred following matching and nonmatching comparisons. In any event, the present findings are in qualitative agreement with results reported by Wilkie and Spetch (1978) with three-key matching and by others with several nonconditional discrimination tasks (e.g., Grice, 1948).

The decrease in matching accuracy that occurred under delayed reinforcement was produced by changes in response rates to both matching and nonmatching comparisons. As with several other temporal variables that have been found to reduce accuracy of one-key matching (see introduction), delayed reinforcement increased rates to nonmatching comparisons. The present study found decreased response rates to the matching comparison with the longer durations of reinforcement delay, and many previous studies (see introduction; Renner, 1964) also have reported slower responding under delayed reinforcement.

Finally, it should be noted that although the present delay procedure did alter performance on the matching task, it is not clear to what extent this was due to delay of reinforcement, delay of timeout, or other factor(s). For example, as delay durations increased, there was a corresponding increase in the time between the sample and the trial outcome, as well as a decrease in the overall rate of reinforcement. Some evidence that delay per se was important comes from additional training given to S-3398. After being trained with a 5-sec sample, 5-sec comparison, and 10-sec delay, this bird was returned to the immediate reinforcement/timeout condition, but with a 15 -sec comparison. Performance on the discrimination quickly improved, and after 25 sessions the discrimination ratio had stabilized at approximately .90 . Ideally, each bird should have received a similar immediate reinforcement condition that was matched to each of its delay conditions. Unfortunately, time constraints prohibited the use of such a design in the present study. Future research on delayed reinforcement effects on matching should attempt to systematically isolate the effects of response-reinforcer delay, per se.

\section{REFERENCES}

Berryman, R., Cumming, W. W., \& Nevin, J. A. (1963). Acquisition of delayed matching in the pigeon. Journal of the Experimental Analysis of Behavior, 6, 101-107.

CARTER, D. E., \& Werner, T. J. (1978). Complex learning and information processing by pigeons: A critical analysis. Journal of the $E x$ perimental Analysis of Behavior, 29, 565-601.

Farthing, G. W., Wagner, J. M., Gilmour, S., \& WaXman, H. M. (1977). Short-term memory and information processing in pigeons. Learning \& Motivation, 8, 520-532.

Ferster, C. B., \& HAMmer, C. B. (1965). Variables determining the effects of delay in reinforcement. Journal of the Experimental Analysis of Behavior, 8, 243-252.

GRANT, D. S. (1976). Effect of sample presentation time on long-delayed matching in the pigeon. Learning \& Motivation, 7, 580-590.

GRANT, D. S. (1981a). Short-term memory in the pigeon. In N. E. Spear \& R. R. Miller (Eds.), Information processing in animals: Memory mechanisms (pp. 227-253). Hillsdale, NJ: Erlbaum.

GraNT, D. S. (1981b). Stimulus control of information processing in pigeon short-term memory. Learning \& Motivation, 12, 19-39.

GRICE, G. R. (1948). The relation of secondary reinforcement to delayed reward in visual discrimination learning. Journal of Experimental Psychology, 38, 1-16.

Kendrick, D. F., Rilling, M., \& Stonebraker, T. B. (1981). Stimulus control of delayed matching in pigeons: Directed forgetting. Journal of the Experimental Analysis of Behavior, 36, 241-251.

MAKI, W. S., JR., \& LEITH, C. R. (1973). Shared attention in pigeons. Journal of the Experimental Analysis of Behavior, 19, 345-349.

Morgan, M. J. (1972). Fixed-ratio performance under conditions of delayed reinforcement. Journal of the Experimental Analysis of Behavior, 17, 95-98.

Nelson, K. R., \& Wasserman, E. A. (1978). Temporal factors influencing the pigeon's successive matching-to-sample performance: Short duration, intertrial interval, and retention interval. Journal of the Experimental Analysis of Behavior, 30, 153-162.

Pierce, C. H., Hanford, P. V., \& Zimmerman, J. (1972). Effects of different delay of reinforcement procedures on variable-interval responding. Journal of the Experimental Analysis of Behavior, 18, 141-146.

RENNER, K. E. (1964). Delay of reinforcement: A historical review. Psychological Bulletin, 61, 341-361.

Richards, R. W., \& Bowers, R. L. (1985). Dual-element effects in a one-key matching task with simultaneous and sequential elements. The Psychological Record, 35, 575-582.

Riley, D. A. (1984). Do pigeons decompose stimulus compounds? In H. L. Roitblat, T. G. Bever, \& H. S. Terrace (Eds.), Animal cognition (pp. 333-350). Hillsdale, NJ: Erlbaum.

RoberTs, W. A., \& GRANT, D. S. (1976). Studies of short-term memory in the pigeon using the delayed matching to sample procedure. In D. L. Medin, W. A. Roberts, \& R. T. Davis (Eds.), Processes of animal memory (pp. 79-112). Hillsdale, NJ: Erlbaum.

Roberts, W. A., \& Kraemer, P. J. (1982). Some observations of the effects of intertrial interval and delay on delayed matching to sample in pigeons. Journal of Experimental Psychology: Animal Behavior Processes, 8, 342-353.

Stonebraker, T. B., \& Rilling, M. (1982). Control of delayed matching-to-sample performance using directed forgetting techniques. Animal Learning \& Behavior, 9, 196-201.

Wasserman, E. A. (1976). Successive matching-to-sample in the pigeon: Variations on a theme by Konorski. Behavior Research Methods \& Instrumentation, 8, 278-282.

Wilkie, D. M., \& Spetch, M. A. (1978). The effect of sample and comparison ratio schedules on delayed matching to sample in the pigeon. Animal Learning \& Behavior, 6, 273-278.

(Manuscript received for publication September 12, 1985.) 